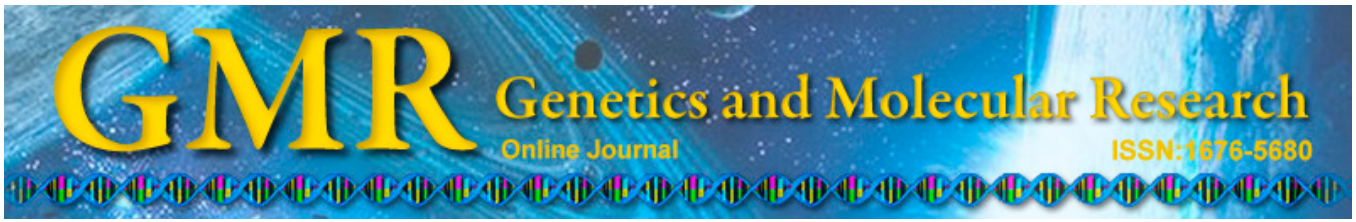

\title{
Association between PAI-1 polymorphisms and plasma PAI-1 level with sepsis in severely burned patients
}

\author{
Y.F. Chi ${ }^{1}$, J.K. Chai ${ }^{1}$, Y.M. Yu ${ }^{2,3}$ H.M. Luo ${ }^{1}$, Q.X. Zhang ${ }^{1}$ and R. Feng ${ }^{1}$ \\ ${ }^{1}$ Department of Burn and Plastic Surgery, \\ First Hospital Affiliated to Peoples Liberation Army General Hospital, \\ Beijing, China \\ ${ }^{2}$ Shriners Hospitals for Children, Boston, MA, USA \\ ${ }^{3}$ Department of Surgery, Massachusetts General Hospital, \\ Harvard Medical School, Boston, MA, USA \\ Corresponding author: Y.F. Chi \\ E-mail: chiyunfei_cyf@163.com
}

Genet. Mol. Res. 14 (3): 10081-10086 (2015)

Received November 28, 2014

Accepted April 6, 2015

Published August 21, 2015

DOI http://dx.doi.org/10.4238/2015.August.21.15

\begin{abstract}
We investigated the association between plasminogen activator inhibitor-1 (PAI-1) polymorphisms and plasma PAI-1 level with sepsis in severely burned patients. A total of 182 patients with burn areas lager than $30 \%$ of the body surface area were enrolled in this study. Peripheral blood samples were obtained from 103 patients with sepsis (sepsis group) and 79 patients without sepsis (control group). An allele-specific polymerase chain reaction assay was used to determine PAI-1 polymorphism $4 \mathrm{G} / 5 \mathrm{G}$ distribution. Plasma PAI-1 levels were detected using an enzyme-linked immunosorbent assay. The frequency of the $4 \mathrm{G} / 4 \mathrm{G}$ genotype and the $4 \mathrm{G}$ allele frequency in the sepsis group were 42.7 and $62.1 \%$ respectively, which were significantly higher than those in the control group $(\mathrm{P}<0.05)$. Sepsis patients had a significantly higher plasma PAI-1 level than the control group $(\mathrm{P}<0.05)$. Compared
\end{abstract}


with the $5 \mathrm{G} / 5 \mathrm{G}$ genotype, PAI-1 concentrations were significantly higher in the $4 \mathrm{G} / 4 \mathrm{G}$ genotype $(\mathrm{P}<0.05)$. The study indicates that the $4 \mathrm{G} / 5 \mathrm{G}$ promoter polymorphism of PAI-1 gene may be related to the susceptibility to burn sepsis and that the $4 \mathrm{G} / 4 \mathrm{G}$ genotype may be an important genetic risk factor of burn sepsis. Additionally, PAI-1 concentrations in the serum are increased in patients with burn sepsis.

Key words: Burn; Plasminogen activator inhibitor-1; Polymorphism; Sepsis

\section{INTRODUCTION}

Sepsis is a systemic inflammatory syndrome caused by infection through a reaction of infection factors. Sepsis is among the most common reasons for admission to intensive care units worldwide. Over the last 2 decades the incidence of sepsis in the USA has tripled and is now the 10th leading cause of death (Angus et al., 2001; Martin et al., 2003). Sepsis is the culmination of complex interactions between the infecting microorganism and the host immune, inflammatory, and coagulation responses (Lawson et al., 1997). The content and activity changes of plasminogen activator inhibitor-1 (PAI-1) influence coagulation. Key to an understanding of sepsis is the recognition of the fact that the proinflammatory and procoagulant responses can be amplified by secondary ischemia (shock) and hypoxia (lung injury) through the release of tissue factor and PAI-1 (Lawson et al., 1997). Additionally, some studies showed that PAI-1 level and activity was altered in patients with sepsis (Menges et al., 2001; Haralambous et al., 2003), while the $4 \mathrm{G} / 5 \mathrm{G}$ promoter polymorphism of PAI-1 gene influenced the transcription rate of PAI-1 and the activity of plasminogen activator inhibitor. In this study, we investigated the impact of $4 \mathrm{G} / 5 \mathrm{G}$ polymorphisms in PAI- 1 on the susceptibility to sepsis as well as determined the serum PAI-1 level in severely burned patients.

\section{MATERIAL AND METHODS}

\section{Subjects}

This clinical study included patients with burns covering more than $30 \%$ of the total body surface area. One hundred eighty-two patients were recruited from the First Hospital Affiliated to Peoples Liberation Army General Hospital from From January 2011 to September 2014. The diagnosis in all cases was made by 2 independent physicians according to sepsis definitions and diagnosis standards (Vincent, 2002). The protocol was approved by the Ethical Review Committees of our hospital. Written informed consent for participation was obtained from each patient. After admission, patients were divided into 2 groups. The sepsis group was composed of 103 burned patients complicated with sepsis, including 83 males and 20 females aged $34.4 \pm 10.2$ years. The 79 burned patients without complicated sepsis comprised the control group, which included 60 males and 19 females aged $34.8 \pm 9.6$ years. There were no significant differences between the 2 groups in the traumatic condition, therapeutic factor, gender, average age, and race $(\mathrm{P}>0.05)$. 


\section{Methods}

\section{Determination of PAI-1 polymorphism 4G/5G by allele specific polymerase chain reaction}

Two milliliters fasting venous blood was collected in an ethylenediaminetetraacetic acid vaccutainer from the sepsis and control groups on the first day after injury. Genomic DNA was isolated using a standard phenol-chloroform method and stored at $-20^{\circ} \mathrm{C}$. For the insertion 5G allele, the primer was: 5'-GTC TCC ACA CGT GGG GG-3', and the deletion 4G allele primer was: 5'-GTC TGG ACA CGT GGG G-3'. Each primer was used in separate polymerase chain reactions (PCRs), but in combination with a common downstream primer 5'-TGC AGC CAG CCA CGT GAT TGT CTAG-3' and the control upstream primer 5'-AAG CTT TTA CCA TGG TAA CCC CTG GT-3', to verify the occurrence of DNA amplification in the absence of the allele on the genomic DNA. Each subject's DNA was run in 3 different PCR systems at the same time. The PCR conditions of the $4 \mathrm{G}$ genotype were: denaturation at $94^{\circ} \mathrm{C}$ for $5 \mathrm{~min}$, denaturation at $94^{\circ} \mathrm{C}$ for $35 \mathrm{~s}$, followed by renaturation at $65^{\circ} \mathrm{C}$ for $35 \mathrm{~s}$, elongation at $72^{\circ} \mathrm{C}$ for $70 \mathrm{~s}$, and elongation at $72^{\circ} \mathrm{C}$ for $5 \mathrm{~min}$, for 30 cycles. The conditions for the $5 \mathrm{G}$ genotype were: denaturation at $94^{\circ} \mathrm{C}$ for $5 \mathrm{~min}$, denaturation at $94^{\circ} \mathrm{C}$ for $35 \mathrm{~s}$, followed by renaturation at $65^{\circ} \mathrm{C}$ for $35 \mathrm{~s}$, elongation at $72^{\circ} \mathrm{C}$ for $70 \mathrm{~s}$ for 10 cycles, and the annealing temperature was changed to $58^{\circ} \mathrm{C}$ for 22 cycles, followed by elongation at $72^{\circ} \mathrm{C}$ for $5 \mathrm{~min}$. PCR products were separated by $2 \%$ agarose gel electrophoresis (Figure 1 ).

\section{Detection of plasma PAI-1 levels by enzyme-linked immunosorbent assay}

Venous blood samples were centrifuged and the plasma was stored at $-80^{\circ} \mathrm{C}$ until measurement of the PAI-1 levels. The plasma level of PAI-1 was measured using an Assay Max Human Plasminogen Activator Inhibitor-1 enzyme-linked immunosorbent assay kit (AssayPro, St. Charles, MO, USA) following the manufacturer protocol.

\section{Statistical analysis}

Statistical analysis was performed using the SPSS version 20.0 software (SPSS, Inc., Chicago, IL, USA). Data were presented as the median and range or mean standard deviation, depending on whether data were normally distributed. The $t$-test was used to compare the clinical features between the sepsis patients and controls. Chi-square tests were used to analyze the genotype frequency and demographic distributions between cases and controls and to evaluate the Hardy-Weinberg equilibrium. Differences of $\mathrm{P}<0.05$ were considered to be statistically significant.

\section{RESULTS}

\section{Determination of PAI-1 polymorphism}

The PCR products were separated by $2 \%$ agarose gel electrophoresis, and the $4 \mathrm{G} / 4 \mathrm{G}$, $4 \mathrm{G} / 5 \mathrm{G}$, and $5 \mathrm{G} / 5 \mathrm{G}$ genotype special bands are shown in Figure 1 . In the $5 \mathrm{G} / 5 \mathrm{G}$ genotype polymerase chain reactions resulted in amplification of 140 base pairs DNA fragment, in the 4G/4G genotype only 139 base pairs DNA fragment was amplified. 


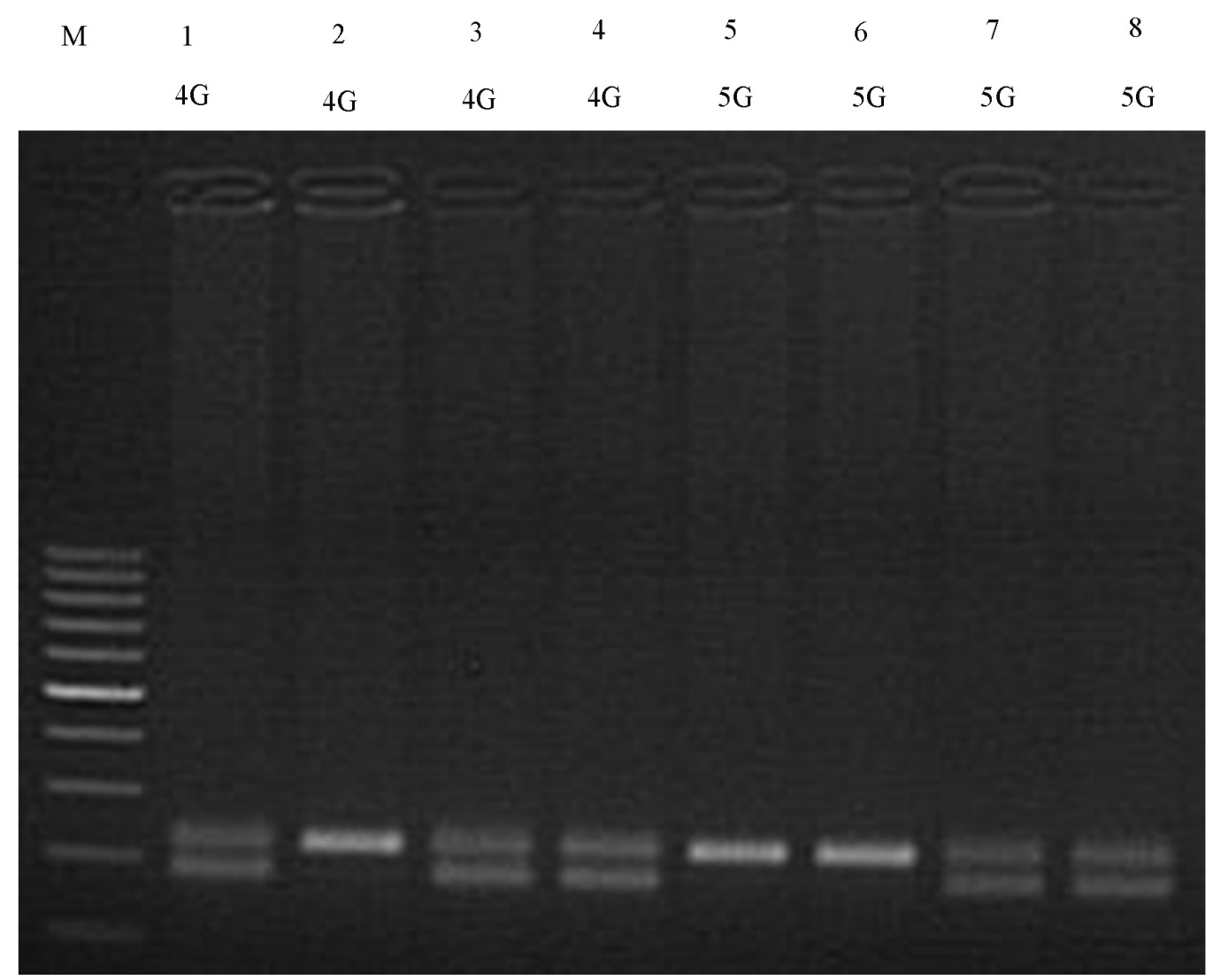

Figure 1. Genotypic analysis of the AAS-PCR for $4 \mathrm{G} / 5 \mathrm{G}$ promoter polymorphism in the PAI-1 gene. Lanes 1-3= 4G/4G genotype; lanes 4 and $5=4 \mathrm{G} / 5 \mathrm{G}$ genotype; lanes $6-9=5 \mathrm{G} / 5 \mathrm{G}$ genotype.

\section{Relationship between PAI-1 polymorphism and burned sepsis}

A goodness of fit test for the genotype frequency showed that the genotype distribution was consistent with Hardy-Weinberg equilibrium in both the sepsis and control groups (P $>0.05$ ). The randomness of samples was good and appeared to be representative of the general population. Compared with the control group, the frequency of the PAI-1 4G/4G genotype increased $\left(\chi^{2}=6.8, \mathrm{P}<0.05\right)$; the carrier frequency of the PAI-1 5G/5G genotype decreased $\left(\chi^{2}=4.2, \mathrm{P}<0.05\right)$; and the carrier frequency of the PAI-1 4G allele improved $\left(\chi^{2}=4.2, \mathrm{P}<\right.$ $0.05)$ in the sepsis group (Table 1).

Table 1. Distribution of genotypes and alleles of PAI-1 in the 2 groups.

\begin{tabular}{lccccc}
\hline Group & \multicolumn{3}{c}{ Genotype frequencies } & & \multicolumn{2}{c}{ Allele frequencies } \\
\cline { 2 - 5 } & $4 \mathrm{G} / 4 \mathrm{G}$ & $4 \mathrm{G} / 5 \mathrm{G}$ & $5 \mathrm{G} / 5 \mathrm{G}$ & & $4 \mathrm{G}$ \\
\hline Sepsis group & $44(42.7)$ & $40(38.8)$ & $19(18.4)$ & $(62.1)^{*}$ & $(37.9)$ \\
Control group & $17(21.5)^{*}$ & $37(46.8)$ & $25(31.6)^{*}$ & $(44.9)$ & $(55.1)$ \\
\hline
\end{tabular}

$* \mathrm{P}<0.05$ compared with control group. 


\section{Comparison of serum PAI-1 levels between the 2 groups}

Serum PAI-1 levels $(57.9 \pm 14.1 \mu \mathrm{g} / \mathrm{L})$ in the sepsis group were higher than those in the control group $(45.9 \pm 10.1 \mu \mathrm{g} / \mathrm{L})$, and the difference was statistically significant $(t=6.96, \mathrm{P}<0.05)$.

\section{Comparison of serum PAI-1 levels among genotypes}

The 4G homozygote serum PAI-1 levels $(62.9 \pm 14.5 \mu \mathrm{g} / \mathrm{L})$ were higher than for the $5 \mathrm{G}$ homozygote $(57.9 \pm 12.1 \mu \mathrm{g} / \mathrm{L})$, and the results were significantly different $(t=8.41$, $\mathrm{P}<0.05$ ). Additionally, the $4 \mathrm{G} / 5 \mathrm{G}$ heterozygote serum PAI-1 levels were between the 2 homozygote levels.

\section{DISCUSSION}

Sepsis is defined as suspected or proven infection plus a systemic inflammatory response syndrome (Bone et al., 1992). Sepsis often progresses when the host cannot contain the primary infection, a problem most often related to characteristics of the microorganism, such as a high burden of infection and the presence of superantigens and other virulence factors, resistance to opsonization and phagocytosis, and antibiotic resistance. When host responses to infection are inadequate, sepsis with organ dysfunction occurs (Russell, 2006). Altered signaling pathways in sepsis ultimately lead to tissue injury and multiorgan dysfunction, contributing to morbidity and mortality. Septic shock and multiorgan dysfunction are the most common causes of death in patients with sepsis (Russell et al., 2000).

In the present study, we investigated the effect of 2 PAI-1 gene polymorphisms on the risk of sepsis in severely burned patients. PAI-1 has been shown to be crucial for the plasminogen activator/plasmin protease system (Cale and Lawrence, 2007). There are many reports indicating that several common polymorphisms in the PAI-1 gene are risk factors for various diseases related to elevated serum levels of PAI-1 (Lin et al., 2009; Sogutlu Sari et al., 2014). However, few studies have investigated the association between PAI-1 polymorphisms and the risk of sepsis in severely burned patients.

Our study revealed that polymorphisms were related to sepsis in burned patients on the genetic level. The frequency of the $4 \mathrm{G} / 4 \mathrm{G}$ genotype and the $4 \mathrm{G}$ allele frequency were 42.7 and $62.1 \%$, respectively, in the sepsis group, and 21.5 and $44.9 \%$ in the control group. There was a statistically significant difference between the 2 groups. Another important aspect of sepsis is the alteration of the procoagulant-anticoagulant balance, with an increase in procoagulant factors and decrease in anticoagulant factors (Russell, 2006).

In conclusion, our results indicate that the PAI-1 promoter polymorphisms $4 \mathrm{G} / 5 \mathrm{G}$ and plasma PAI-1 level are associated with sepsis risk in burned patients. The PAI-1 4G/5G polymorphisms may be important hereditary factors responsible for sepsis development in burned patients, which may be used to prevent the development of burned sepsis.

\section{REFERENCES}

Angus DC, Linde-Zwirble WT, Lidicker J, Clermont G, et al. (2001). Epidemiology of severe sepsis in the United States: analysis of incidence, outcome, and associated costs of care. Crit. Care Med. 29: 1303-1310.

Bone RC, Balk RA, Cerra FB, Dellinger RP, et al. (1992). Definitions for sepsis and organ failure and guidelines for the use of innovative therapies in sepsis. The ACCP/SCCM Consensus Conference Committee. American College of 
Chest Physicians/Society of Critical Care Medicine. Chest 101: 1644-1655.

Cale JM and Lawrence DA (2007). Structure-function relationships of plasminogen activator inhibitor-1 and its potential as a therapeutic agent. Curr. Drug Targets 8: 971-981.

Haralambous E, Hibberd ML, Hermans PW, Ninis N, et al. (2003). Role of functional plasminogen-activator-inhibitor-1 $4 \mathrm{G} / 5 \mathrm{G}$ promoter polymorphism in susceptibility, severity, and outcome of meningococcal disease in Caucasian children. Crit. Care Med. 31: 2788-2793.

Lawson CA, Yan SD, Yan SF, Liao H, et al. (1997). Monocytes and tissue factor promote thrombosis in a murine model of oxygen deprivation. J. Clin. Invest. 99: 1729-1738.

Lin S, Huiya Z, Bo L, Wei W, et al. (2009). The plasminogen activator inhibitor-1 (PAI-1) gene -844 A/G and -675 4G/5G promoter polymorphism significantly influences plasma PAI-1 levels in women with polycystic ovary syndrome. Endocrine 36: 503-509.

Martin GS, Mannino DM, Eaton S and Moss M (2003). The epidemiology of sepsis in the United States from 1979 through 2000. N. Engl. J. Med. 348: 1546-1554.

Menges T, Hermans PW, Little SG, Langefeld T, et al. (2001). Plasminogen-activator-inhibitor-1 4G/5G promoter polymorphism and prognosis of severely injured patients. Lancet 357: 1096-1097.

Russell JA (2006). Management of sepsis. N. Engl. J. Med. 355: 1699-1713.

Russell JA, Singer J, Bernard GR, Wheeler A, et al. (2000). Changing pattern of organ dysfunction in early human sepsis is related to mortality. Crit. Care Med. 28: 3405-3411.

Sogutlu Sari E, Yazici A, Eser B, Erol MK, et al. (2014). The prevalence of 4G/5G polymorphism of plasminogen activator inhibitor-1 (PAI-1) gene in central serous chorioretinopathy and its association with plasma PAI-1 levels. Cutan. Ocul. Toxicol. 33: 1-5.

Vincent JL (2002). Sepsis definitions. Lancet Infect. Dis. 2: 135. 